\title{
POLÍTIQUES D'HABITATGE SOCIAL I DE JOVES
}

\author{
Carme Trilla i Bellart ${ }^{1}$ \\ Secretària d'Habitatge \\ Generalitat de Catalunya
}

Remisión Artículo: 15-10-2007

Palabras Clave: política d'habitatge, habitatge social i de joves, demanda d'habitatge,

Resumen: L'objectiu d'aquest article és tractar les inquietuds que han aparegut en els darrers vint anys que tenen a veure amb les dificultats d'accés a l'habitatge per part de determinats col-lectius, entre els quals destaca el dels joves, i amb les condicions de vida d'aquests col-lectius. Ja no es tracta de fer front a una insuficiència global d'habitatges, sinó a una desproporció desconeguda entre el cost de l'habitatge i els salaris, desproporció, lògicament més exagerada en el cas de salaris per sota de la mitjana com són habitualment els dels joves. Allí on fins als anys 90 la política d'habitatge es plantejava problemes de caire físic, de producció, sorgeix un problema de caràcter econòmic i financer, en front del qual la política d'habitatge havia de repensar els seus instruments. No és que amb anterioritat a aquestes dates els problemes econòmics d'accés a l'habitatge no existissin sinó que a començaments dels anys 90 -com avui- els problemes econòmics esdevenen aclaparadors per a una part molt important de la població. Aquestes noves problemàtiques de dificultat econòmica d'accés a l'habitatge dels joves adquireixen una dimensió política i social important perquè tenen unes derivades de conseqüències funestes, com són, només en l'àmbit demogràfic, el retard en l'edat d'emancipació, el retard en la formació de noves llars, el retard en la natalitat i la reducció del nombre de fills per mare.

\section{Evolució de la política d'habitatge en els darrers vint anys. De les necessitats genèriques a les necessitats específiques}

La política d'habitatge va ser concebuda durant gairebé la totalitat del segle XX, a Espanya, i a Catalunya, des d'una perspectiva global, enfocada cap al conjunt de la població. Els objectius eren superar els dèficits d'allotjament, històrics o sobrevinguts a causa de forts moviments migratoris, que encara s'enregistraven en el Cens de població i habitatge de l'any 1981. La mesura del dèficit era la constatació d'un nombre superior de llars que d'habitatges, cosa evidentment delatora de situacions de manca d'habitatge -o de manca d'un allotjament definible com a habitatge-, o delatora de situacions d'amuntegament per la convivència de més d'una llar en el mateix habitatge. En efecte, per donar cabuda a les 10.224.833 llars, el Cens de 1981 enregistrava 10.024 .740 habitatges principals a Espanya, amb un dèficit de 200.000 habitatges, i per les 1.768.958 llars de Catalunya, n'enregistrava 1.756.195, amb un dèficit de 13.000 habitatges. Per combatre aquesta situació, des del sector públic es tractava d'establir mesures que tendissin cap a la provisió d'habitatge suficient per fer front a les necessitats d'allotjament globals, sense distinció de tipus de col.lectius i sense distinció d'edats, prioritzant sempre els objectius quantitatius per sobre dels qualitatius. L'única limitació que s'establia per a poder ser inclòs dins el conjunt de persones o llars beneficiàries de les polítiques públiques era el nivell d'ingressos, és a dir que els beneficiaris dels habitatges protegits havien de ser

\footnotetext{
${ }^{1}$ Persona de contacto Secretaria d'Habitatge, correo: mjose.mesequer@gencat.net>
} 
persones amb ingressos acotats. En funció d'aquests objectius, l'instrument utilitzat era bàsicament el foment de la construcció d'habitatges, mitjançant préstecs privilegiats 0 subvencions als promotors d'habitatges de preu limitat (habitatges protegits) i als compradors d'aquests habitatges.

És a partir dels anys 80, coincidint amb la nova estructuració de l'Estat en autonomies i per tant, coincidint amb una visió molt més precisa del territori i de les necessitats de cada àmbit territorial, que comencen a plantejar-se noves inquietuds per a la política d'habitatge a Espanya, i pel que fa a nosaltres, a Catalunya. En primer lloc, inquietuds relatives al manteniment i qualitat del parc d'habitatges, en segon lloc, relatives a problemàtiques especials de subgrups de població: gent jove, gent gran, col.lectius amb problemàtiques específiques, i en tercer lloc, relatives a les condicions de vida dels usuaris dels habitatges.

No és objecte d'aquest article l'anàlisi de les polítiques de rehabilitació que es van introduir a Catalunya a començaments dels anys 80 a partir de la constatació que el parc construït presentava seriosos problemes de manteniment, no forçosament i exclusivament derivats de la seva antiguitat, sinó també de la qualitat de la construcció. Va ser aquest un àmbit d'activitat que calia destapar i que, a manca d'una implicació privada decidida, exigia que fos el sector públic el que fes el primer pas, invertint directament en els parcs propis, i introduint incentius potents per induir una cultura del manteniment i de la rehabilitació entre la població. Avui és evident que aquesta cultura ha estat totalment introduïda a casa nostra, tot i que el suport públic roman necessari, ja no només per fomentar l'activitat, sinó també per donar suport a les llars quan aquesta activitat esdevé excessivament costosa per a llurs capacitats.

Ens centrarem, per tant, en el segon i tercer front d'inquietuds que han aparegut en els darrers vint anys, que tenen a veure amb les dificultats d'accés a l'habitatge per part de determinats col.lectius, entre els quals destaca el dels joves, i amb les condicions de vida d'aquests col.lectius.

Pel que fa als joves, es pot afirmar amb rotunditat que la focalització d'una part important de la política d'habitatge cap a aquest col.lectiu no apareix fins a començaments dels anys 90 i que apareix amb força per unes raons explicatives molt semblants a les del moment actual. Ja no es tracta de fer front a una insuficiència global d'habitatges, sinó a una desproporció desconeguda entre el cost de l'habitatge i els salaris, desproporció, lògicament més exagerada en el cas de salaris per sota de la mitjana com són habitualment els dels joves. Allí on fins als anys 90 la política d'habitatge es plantejava problemes de caire físic, de producció, sorgeix un problema de caràcter econòmic i financer, en front del qual la política d'habitatge havia de repensar els seus instruments. No és que amb anterioritat a aquestes dates els problemes econòmics d'accés a l'habitatge no existissin sinó que a començaments dels anys 90 -com avui- els problemes econòmics esdevenen aclaparadors per a una part molt important de la població. Aquestes noves problemàtiques de dificultat econòmica d'accés a l'habitatge dels joves adquireixen una dimensió política i social important perquè tenen unes derivades de conseqüències funestes, com són, només en l'àmbit demogràfic, el retard en l'edat d'emancipació, el retard en la formació de noves llars, el retard en la natalitat i la reducció del nombre de fills per mare.

A finals de l'any 1991, en el número 85 de la revista Documentación Social, Manolo Montero, Bonifacio Pedraza, Luis Suárez Rufo i Manolo Blanco publicaven l'article "Los jóvenes y la vivienda" en el context d'un monogràfic expressament titulat "La vivienda. ¿Un problema?". En aquest article els autors assenyalaven els principals inconvenients que tenien els joves a Espanya per a accedir a l'habitatge:

- La progressiva disminució de la construcció d'habitatges de protecció oficial.

- La inseguretat en el treball i, en conseqüència, la irregularitat en els fluxos d'ingressos. 
- El retraïment del mercat de lloguer, paral.lel a una evolució alcista dels lloguers.

- El mal estat dels habitatges en lloguer i la seva inadequació a les tipologies demandades pels joves.

- La impossibilitat de comprar pisos al comptat, tal i como succeïa en la majoria de ocasiones.

- La necessitat de disposar prèviament d'una elevada quantitat de diner per a poder sufragar els costos necessaris per a poder constituir un préstec hipotecari (entrada, notari, registre, comissió d'obertura, etc.).

Quinze anys després, l'anomenat "problema de l'habitatge dels joves" no sembla haver desaparegut sinó tot al contrari, tal i como es pot comprovar fent un seguiment periòdic dels mitjans de comunicació.

Per tal de donar una idea de les semblances i les diferències entre els dos moments: 1991/2007, el gràfic adjunt mostra l'evolució de les dificultats d'accés a l'habitatge per a una llar jove a Catalunya, basant-se en la despesa en relació als ingressos mitjans que suposa en cada moment el pagament d'una hipoteca contractada per a un habitatge de preu mitjà.

Evolució del cost d'accés a un habitatge a Catalunya per a una persona jove. 1987-2007

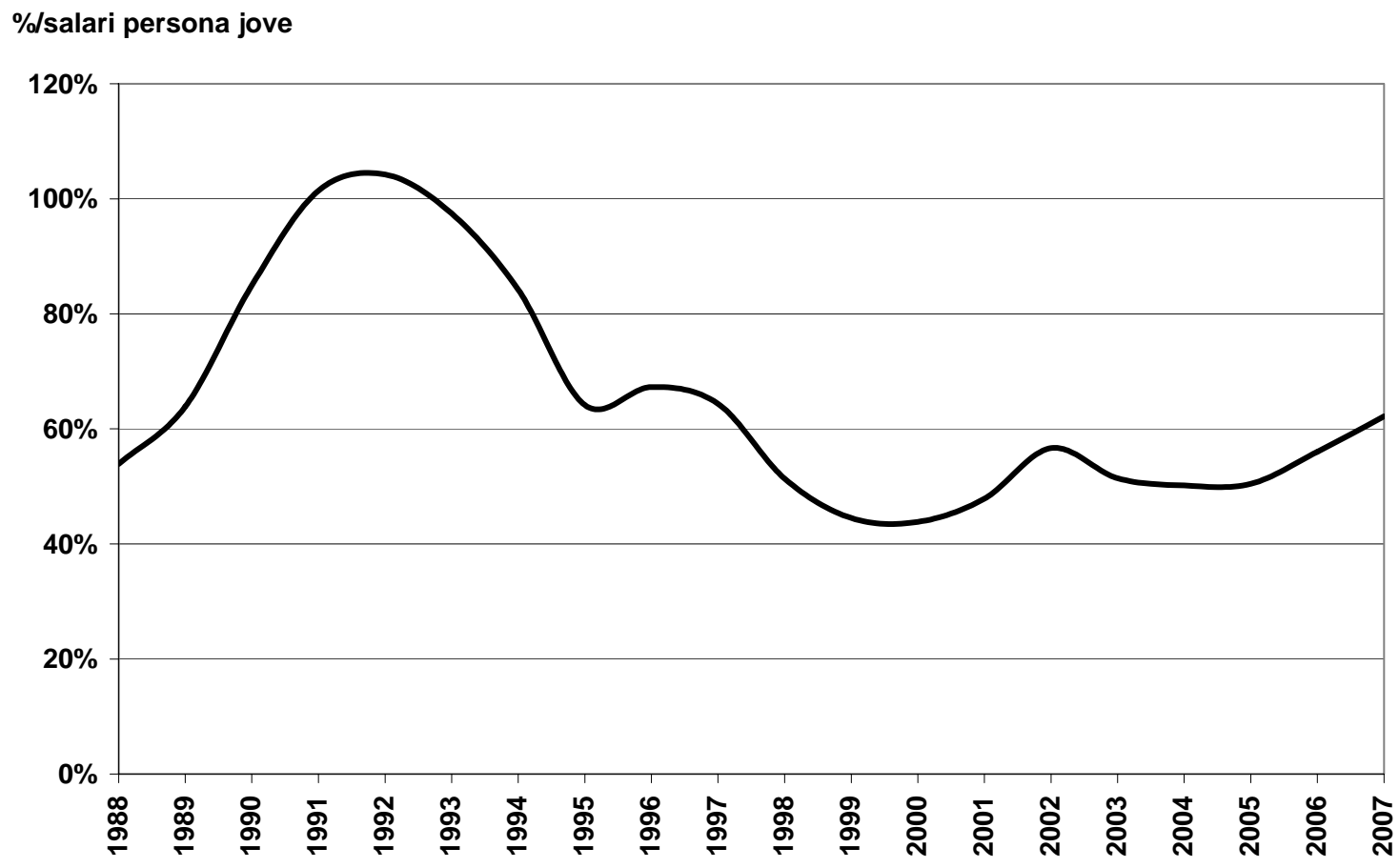

En veient el quadre s'entén que a finals dels anys 80 i principis dels 90 , els responsables de la política d'habitatge haguessin de fer una reflexió sobre la particular dificultat dels joves per accedir a l'habitatge: el pagament d'una hipoteca per a un habitatge de preu mitjà de Catalunya equivalia a més del $100 \%$ dels ingressos d'una persona jove, cosa que impossibilitava del tot la compra d'un habitatge per a la gran majoria de joves. Cal tenir present que en aquells moments el principal element de cost era l'elevat preu de les hipoteques, amb tipus d'interès per sobre del $15 \%$, però també que els preus dels habitatges s'havien gairebé doblat en només tres anys. 
Les mesures que en aquells moments es van prendre van consistir en crear una figura nova d'habitatge protegit més propera als preus de mercat -els anomenats habitatges de preu taxat-, també es van reforçar les subsidiacions dels préstecs per abaratir el cost de les hipoteques i, en el cas de Catalunya, es va afegir a la resta de mesures una subvenció directa a fons perdut per als joves, equivalent al $10 \%$ del preu de venda dels habitatges protegits, entre els quals hi figuraven els de preu taxat.

També a començaments dels anys 90 es va començar a parlar de la necessitat d'un cert volum d'oferta d'habitatge de lloguer per ajudar al procés emancipatori. Aquest tipus d'oferta, però, no ha començat a donar fruit fins ben entrat el segle XXI.

Del gràfic es desprèn que la situació actual dels joves no és, en termes de cost d'accés a I'habitatge, tan greu com la dels primers anys 90 , ja que la proporció teòrica d'ingressos a destinar per part d'un jove al pagament d'una hipoteca se situa en el 62\%. No obstant això, aquest és un percentatge clarament excessiu i que deixa fora del mercat a un volum molt important de joves. I, a més un percentatge excessiu si es té en compte que aprofita fins al límit els avantatges financers que avui dona el mercat lliure i que, per tant, la gravetat prové del preu absolut de l'habitatge. De fet, es podria dir que la gravetat de la situació actual prové de què al llarg d'aquests quinze anys, la manca de solució del problema l'ha anat fent acumulatiu, i ha arribat a proporcions excessives. Concretament, en els treballs realitzats per al Pacte Nacional per a l'Habitatge s'han comptabilitzat 200.000 persones amb necessitat d'habitatge acumulades a dia d'avui a Catalunya.

\section{Les polítiques d'habitatge establertes a partir de l'any 2004. El reconeixement de les especificitats diferencials en la demanda d'habitatge.}

En l'última enquesta realitzada per la Generalitat la principal actuació que els catalans reclamen al Govern, és una actuació decidida en matèria d'habitatge. I això és degut a que hem passat entre els anys 1997 i 2006 una de les fases més intenses de creixement del sector de l'habitatge, amb una gran majoria de la població que ha pogut adquirir o millorar d'habitatge i amb la gran majoria de propietaris vivint la il.lusió de la fortíssima revalorització dels seus habitatges, i tanmateix, al costat d'aquestes millores evidents, s'ha anat desenvolupant al nostre país un fenomen d'important marginació del mercat de moltes de les llars que necessiten accedir a un primer habitatge -singularment els joves-, o d'aquells que necessiten un nou habitatge per raó d'un canvi en la seva estructura familiar, per ser nouvinguts, o per ser persones amb risc d'exclusió. Així veiem com en aquest període els salaris mitjans de Catalunya han crescut un 30\%, mentre que els preus mitjans dels habitatges han pujat entre un $250 \%$ i un $300 \%$, segons les diverses zones del territori, passant dels 1.500 euros $/ \mathrm{m}^{2}$, als 3.280 euros $/ \mathrm{m}^{2}$. En l'entorn metropolità de Barcelona, han passat dels 1.700 euros $/ \mathrm{m}^{2}$, als 3.700 euros $/ \mathrm{m}^{2}$, i a la ciutat de Barcelona, dels 1.900 euros $/ \mathrm{m}^{2}$, s'ha arribat a un preu mitjà de 5.800 euros $/ \mathrm{m}^{2}$.

Des de la perspectiva de la política d'habitatge, aquesta situació de forta inflació -una de les més intenses mai conegudes en la nostra història immobiliària-, ha vingut acompanyada d'una caiguda dràstica en la producció d'habitatges protegits. Des de volums d'entre 15.000 i 20.000 anuals de mitjans dels anys 90 , portem deu anys amb produccions inferiors als 10.000, cosa que ha anat acumulant una molt rellevant demanda insatisfeta.

És aquest doble fenomen el que ha discriminat un sector ampli de la població, que com s'ha dit es xifra en 200.000 persones. Per fer front a aquest difícil problema, Catalunya pateix, però, d'una falta manifesta d'instruments d'intervenció, que constitueix un dels pitjors llegats rebuts. Davant del punt d'inflexió que va significar l'any 1997, amb l'arrencada del més intens i llarg procés inflacionari de l'habitatge al nostre país, les polítiques d'habitatge anteriors a l'any 2004 
no van fer cas dels advertiments que es feien en el sentit del risc implícit de fractura social que el procés incorporava, i van tolerar que s'anés reduint la nova producció d'habitatges protegits. I no van introduir cap gir en els instruments de la política d'habitatge que ajudessin a pal.liar la situació de greuje creixent per a les llars amb ingressos mitjans i baixos en llurs problemàtiques d'accés a l'habitatge.

La normativa que havia de ser decisiva per assegurar sòl per a la producció d'habitatges protegits -la Llei d'Urbanisme de 2002-, va ser irresponsablement restrictiva introduint la obligació de reserves de sòl per a habitatge protegit de forma tímida. Quan altres comunitats autònomes -com, de forma exemplar ho venia fent el País Basc des de mitjan els anys noranta- estaven ja treballant amb aquest crucial instrument en proporcions àmpliament per sobre del $20 \%$, i per a tots els creixements urbans, a Catalunya es va introduir amb els percentatges més baixos d'Espanya i afectant tan sols a municipis que haguessin revisat el seu pla general. D'altra banda, la disciplina de destinació dels sòls municipals a habitatge protegit tampoc va ser considerada una prioritat, de manera que les possibilitats de construcció d'habitatge protegit en sòls municipals s'han vist fortament limitades. Finalment, però no menys important, cal assenyalar la tendència descendent en la gestió de sòl per a habitatge protegit per part de I'INCASÒL que, sense cap estratègia coherent a mitjà i llarg termini, fortament condicionada per la legislació sobre el sòl del govern del PP, va deixar pràcticament inexistents les reserves de sòl públic de la Generalitat.

Així, a la tradicional absència de parc públic d'habitatges al nostre país, que prové de cinquanta anys d'orientació de la política d'habitatge cap a la privatització i que ens situa en un dels últims llocs en el ránking europeu de provisió d'habitatge social, ha vingut a afegir-se en els últims anys la insuficiència de disposició de sòl on encaixar la nova producció d'habitatges protegits de compra o de lloguer.

Amb aquesta situació de partida es troba el nou govern de la Generalitat a començaments de l'any 2004 i, a partir d'aquesta situació sota mínims, se li exigeix, i s'exigeix a si mateix, establir les bases per redreçar la situació, tot i sabent que, en l'àmbit de l'habitatge, els processos urbanístics i de construcció no permeten assegurar resultats tangibles de forma immediata, que és allò que amb tota legitimitat la població reclama.

Es comprèn en aquest sentit el nerviosisme i l'angoixa que professen molts col-lectius, especialment els dels joves, però no és bo caure en l'escepticisme negativista que algunes veus malintencionades han vingut sostenint des del primer moment i des del primer anunci de la bateria de mesures per atacar la situació.

Per fer front a aquesta complicada situació, la política d'habitatge estava obligada a introduir modificacions importants en el seu disseny:

a) ampliar el ventall de població beneficiària

b) canviar els instruments d'intervenció

c) descentralitzar l'atenció de les necessitats i la gestió dels programes

d) incrementar els recursos pressupostaris.

I, aquests canvis s'han anat promovent, a través de cinc grans peces normatives: la Llei d'Urbanisme de l'any 2004 -amb el seu Reglament posterior-, el Pla pel Dret a l'Habitatge 20042007, el Pla de Sòl 2005-2010, el Pacte Nacional per a l'Habitatge 2007-2016, i la Llei del Dret a l'Habitatge que és a punt de ser aprovada pel Parlament de Catalunya. És sobre aquesta sòlida estructura que en els anys venidors s'hauran de sustentar les polítiques d'habitatge i és gràcies a aquesta sòlida estructura que es podrà observar un gir definitiu en la capacitat de resposta del sector públic davant els greus problemes de l'habitatge. 


\section{a) La llei d'Urbanisme de l'any 2004}

D'acord amb el què ja han anat introduint la majoria de comunitats autònomes, i que fins i tot avui recull la nova Llei del Sòl/2007, de l'Estat, la Llei d'Urbanisme 2/2004, de Catalunya, va fer obligatòria la reserva de sòl per a habitatge protegit en tots els nous desenvolupaments urbans, de forma més intensiva en els municipis de més de 10.000 habitants on són exigibles reserves mínims del 20\% per a habitatge amb protecció oficial, i del 10\% per a habitatge de preu concertat, i de forma menys exigent en els municipis de menys de 10.000 habitants, on només són exigibles reserves mínimes per a habitatge amb protecció oficial.

Sens dubte, aquesta és una peça clau de l'estructura d'intervenció pública, i és la veritable peça que assegura que en el futur la provisió d'habitatges protegits a Catalunya no es pugui veure estrangulada per una manca de sòl a preu raonable i encaixable dins els paràmetres de preus màxims de la protecció oficial.

El recompte fet en motiu del Pacte Nacional per a l'Habitatge sobre sòls que ja han passat un procés de planificació urbanística, en virtut del qual se'ls ha exigit l'establiment de reserves, dóna un total potencial aproximat de 103.000 habitatges.

\section{b) El Pla per al Dret a l'Habitatge}

L'escassa producció d'habitatge protegit ha anat progressivament deixant en situació d'exclusió del mercat i amb risc d'exclusió social a col.lectius que en altres circumstàncies històriques veien solventada la seva situació amb la provisió d'habitatge protegit en quantitats suficients. Per a aquests segments, per sota de les 3,5 vegades el SMI, la política d'habitatge actual ha introduït nous instruments, com els habitatges dotacionals públics, els ajuts al pagament del lloguer, els habitatges d'inclusió, els avals per a la contractació d'habitatges en lloguer. La gran majoria d'aquests instruments i recursos públics s'adrecen a població entre 18 i 35 anys.

En l'extrem contrari, el problema de l'accés a l'habitatge impregna avui totes les esferes del mercat immobiliari $\mathrm{i}$ ha fet que els sectors habituals en els que tradicionalment actuava la política d'habitatge, que eren les capes de població amb rendes més baixes, s'hagin vist superats, en afectar les problemàtiques actuals a àmplies franges de classes mitjanes amb ingressos per sobre dels considerats habitualment com elegibles per tenir dret a ajuts públics. Més enllà de la població habitual beneficiària de la política d'habitatge, que es situava per sota de les 3,5 vegades el salari mínim, avui hem de donar resposta a població fins a 6,5 vegades el salari mínim, cosa que obliga a incrementar els recursos pressupostaris, i a dissenyar noves mesures més adequades als nous requeriments, com els habitatges de preu concertat, els préstecs protegits a tipus fix amb quotes creixents, els avals per la contractació de préstecs hipotecaris d'emancipació, o de compra d'habitatge a preu acotat.

El Pla pel Dret a l'Habitatge 2004-2007 establia les línies de reforma d'algunes de les subvencions ja existents anteriorment que seguien tenint un valor de foment d'activitat, com les adreçades a la promoció d'habitatge, especialment de lloguer, o a la rehabilitació d'habitatges, adaptant-les a la nova situació i corregint ineficiències que s'havien fet paleses en els darrers anys.

Però, el Pla per al Dret a l'Habitatge també introduïa noves línies per fer front als nous reptes, com les subvencions a ajuntaments $i$ entitats sense ànim de lucre per a la compra de sòl per a habitatge protegit, les subvencions per al pagament del lloguer per llars amb ingressos baixos, i els ajuts per a propietaris que posessin habitatges desocupats en lloguer. 
Els resultats d'aquest conjunt d'ajuts per al període 2004-primer semestre del 2007 han començat a dibuixar un horitzó de recuperació de vitalitat en la intervenció pública en l'habitatge:

. S'han qualificat 25.000 habitatges amb protecció oficial i l'INCASÒL en té 12.000 en projecte, resultat de convenis amb ajuntaments, cosa que fa pensar que a final d'any s'haurà complert amb escreix el compromís del Govern anterior de promoure 42.000 habitatges de protecció oficial en el quadrienni 2004-2007.

Per primera vegada enguany, des de l'any 1999, la xifra d'habitatges protegits iniciats superarà el $10 \%$ del total d'inicis d'habitatges a Catalunya.

. Els ajuntaments $\mathrm{i}$ els promotors sense ànim de lucre han augmentat extraordinàriament la seva participació en aquesta promoció d'habitatges amb protecció oficial, passant del $44 \%$, a prop del $60 \%$ del total.

. S'han concedit subvencions a ajuntaments i entitats sense ànim de lucre per la compra de sòl per a prop de 3.000 habitatges.

. S'hauran aprovat ajuts per a la rehabilitació de 50.000 habitatges.

. S'hauran aprovat ajuts per a la instal.lació de 1.800 ascensors, que donen servei a més de 30.000 habitatges.

. S'han mobilitzat 10.000 habitatges desocupats, mitjanant l'activitat de mediació de les borses de lloguer social i de lloguer jove.

. S'hauran aprovat ajuts per al pagament del lloguer per a prop de 14.000 llars.

. S'han concedit 1.600 ajuts personalitzats a llars o persones en risc de pèrdua de l'habitatge.

Els nous instruments en la major part dels casos suposen una atenció personalitzada dels ciutadans en la seva relació amb l'habitatge i requereixen una proximitat desconeguda en la política d'habitatge tradicional.

En aquest sentit, en el context del Pla, s'introduïa una nova manera d'operar en les relacions de la política d'habitatge entre la Generalitat i els ajuntaments, obrint Oficines Locals d'Habitatge, de les que avui se'n compta amb 89 (en municipis de més de 5.000 habitants, i consells comarcals), i establint una xarxa de Borses de Mediació entre propietaris i llogaters per al lloguer d'habitatges, de les que n'hi ha en aquest moment 47.

Finalment, però en aquest cas, el més important per poder donar una veritable viabilitat al conjunt de mesures exposades, és el necessari reforç del finançament de la política d'habitatge. En aquest sentit el progrés que ha seguit el pressupost de la Secretaria d'Habitatge en el període 2004-2007 ha estat molt important, passant dels 60 milions d'euros dels anys 2003 i 2004, als 78,5, de l'any 2005 (+30\%), als 108, de l'any $2006(+37,5 \%)$, i als 136, de l'any 2007 (+26\%), és a dir un increment global del 127\%. També per part del Ministerio de Vivienda els recursos destinats a Catalunya han crescut, des de valors de 28 milions d'euros, dels anys 2004 i 2005, a 39 milions, l'any 2006 i a 51 milions, l'any 2007 (un 82\% global). 


\section{El Pla de Sòl 2005-2010}

El Pla de Sòl de la Generalitat, per la seva banda, assenyalava les possibles ubicacions en les que l'Institut Català del Sòl podia desenvolupar, en col.laboració amb els ajuntaments afectats, una tasca de transformació de sòls no residencials en sòls per a habitatge amb uns percentatges de participació majoritària d'habitatge protegit.

En el període 2005 a 2007, les tasques dutes a terme per l'INCASÒL en desenvolupament del Pla estratègic de Sòl, han donat com a resultat acords amb ajuntaments i propietaris de sòl amb un potencial de 25.000 habitatges amb protecció oficial, cosa que suposa un salt endavant, respecte d'una situació d'una pràctica absència de sòls futurs en mans de l'Institut.

Però aquest Pla ha estat també reenfocat en virtut dels treballs d'elaboració del Pacte Nacional per a l'Habitatge, i se l'ha situat en una perspectiva de deu anys, fins a l'horitzó 2016, amb la qual cosa s'ha marcat un objectiu d'obtenció de sòls per a 54.000 habitatges protegits dins un context de sòl per a 113.000 habitatges.

\section{d) El Pacte Nacional per a l'Habitatge 2007-2016}

Els resultats efectius de les diverses vies d'actuació comentades fins aquí són molt diferents, ja que n'hi ha que tenen una plasmació immediata, i per tant, són tangibles en el molt curt termini, com és el cas concret dels ajuts al lloguer, o els ajuts per a la rehabilitació d'habitatges.

Altres mesures, en canvi, donen resultats a mig termini, com són les negociacions amb propietaris per convèncer-los que posin els seus habitatges en lloguer, o les negociacions amb ajuntaments per què mobilitzin i incrementin els seus sòls disponibles per fer habitatge protegit; i encara n'hi a d'altres que només tindran resultat a molt llarg termini, com és el cas del Pla de Sòl esmentat, o la mobilització de sòls obligatoris per a habitatge protegit que va generant l'aprovació dels planejaments urbanístics, a partir de l'entrada en vigor de la llei d'Urbanisme de Catalunya del 2004.

Aquest diferent ritme en la capacitat de resposta dels instruments de la política d'habitatge per fer front a problemes que semblen demanar molta immediatesa, ens situa avui davant la necessitat d'operar en un triple nivell de projecció temporal, amb el reforçament del Pla per al Dret a l'Habitatge, allargant-lo fins a l'any 2010, el reforçament i agilitació del Pla de Sòl de la Generalitat i el Pacte Nacional per a l'Habitatge de Catalunya, per a un període de 10 anys, 2007-2016.

En concret, el Pacte Nacional per a l'Habitatge 2007-2016, preveu un important paquet de mesures de cara a afavorir l'accés a l'habitatge dels joves. El Repte 1 del Pacte enfoca justament aquesta problemàtica, reconeixent que es tracta del problema d'habitatge amb un major volum de població afectada, amb 200.000 llars avui amb necessitat d'habitatge assequible "retinguda" i amb una previsió de 27.000 noves necessitats anuals d'ajuts públics, derivades de la formació mitjana de 40.000 noves llars per any, en els propers deu anys.

Entre les mesures que s'han ja decretat i les que derivaran dels nous programes, es troben l'increment de la promoció d'habitatge protegit especialment de lloguer, el reforç de la xarxa de Borses Joves d'Habitatge, dels ajuts als joves per al pagament del lloguer, i dels crèdits per a l'emancipació de joves. 
El Pacte estableix, en efecte, com a Repte primer, millorar l'accés a l'habitatge, especialment del joves:

- Mitjançant la mobilització de sòl per a 250.000 habitatges amb protecció oficial, això és, sòls que, per raons urbanístiques o de mercat, es puguin obtenir a uns preus que encaixin dins dels topalls màxims que la normativa de protecció oficial determina per als habitatges protegits.

- Mitjançant la construcció de 160.000 habitatges amb protecció oficial, especialment per a joves que s'han d'emancipar.

- I mitjançant la mobilització i posada en el mercat, de 62.000 habitatges del parc desocupat i l'increment dels ajuts directes fins a 140.000 llars per al pagament del lloguer, per a la rehabilitació del primer habitatge, per a la compra del primer habitatge, per al foment de la copropietat, o per a afavorir l'emancipació dels joves.

Sens dubte, caldria que aquestes mesures fossin efectives en el molt curt termini per donar solució a moltes situacions familiars difícils; algunes mesures malauradament, tenen processos de maduració lents, com és el cas de la recuperació de cotes suficients de producció d'habitatges assequibles (amb protecció oficial), i per aquesta raó, el Govern de la Generalitat ha decidit fer un esforç pressupostari important en els àmbits dels ajuts directes a les famílies en el lloguer i la compra, com a primer pas i immediat per a l'alleugeriment de la tensió.

\section{e) Llei del Dret a l'Habitatge}

Com a necessari complement de les polítiques d'habitatge descrites fins aquí que tenen una vocació de correcció de les disfuncions conjunturals del mercat, el projecte de Llei del Dret a l'Habitatge de Catalunya, amb una visió estructural del sector de l'habitatge, vol introduir un canvi d'enfocament transcendental dels conceptes d'habitatge, de la funció social de l'habitatge i de la relació de la societat amb el parc d'habitatges existent. La Llei pretén anar més enllà de les tradicionals mesures de mer foment a la construcció, adquisició o rehabilitació de l'habitatge que s'han vingut aplicant fins ara, i transformar el mercat de l'habitatge de la forma més estructural possible.

En el context del Pacte Nacional per a l'Habitatge, la Llei del Dret a l'Habitatge fornirà instruments fonamentals per fer possibles compromisos que no podrien complir-se si no fos amb canvis legislatius profunds, entre els quals sobresurten l'obligació als municipis d'avançar cap a un horitzó en el que el $15 \%$ dels parcs d'habitatge siguin destinats a polítiques socials, o l'obligació per a la Generalitat d'instaurar un sistema de prestacions públiques per al pagament dels habitatges per a les persones amb ingressos baixos, o l'obligació de l'adjudicació dels habitatges protegits a través d'un registre públic.

Estem convençuts que amb aquesta bateria de mesures i instruments es capgirarà la situació actual, i que els joves entraran en una etapa en la què l'habitatge deixarà de ser un obstacle per a emancipar-se quan així ho decideixin. 
Architecture, City, and Environment

Arquitectura, Ciudad y Entorno 